J. Clin. Chem. Clin. Biochem.

Vol. 27, 1989, pp. 57-63

(C) 1989 Walter de Gruyter \& Co.

Berlin - New York

\title{
Determination of Soluble Fibrin by Turbidimetry of its Protamine Sulphate-Induced Paracoagulation
}

\author{
By J. U. Wieding, Gundel Eisinger and $H$. Köstering
}

Hämatologie, Universitätsklinik, Göttingen, FRG

(Received June 9/October 10, 1988)

Summary: Protamine sulphate-induced aggregation of soluble fibrin causes an increase of turbidity in the plasma sample, which can be measured by means of kinetic turbidimetry.

A method was developed which is sufficiently sensitive for the determination of soluble fibrin in plasma without interfering with the sensitivity for fibrinogen. The performance of the assay was studied by analysing plasma samples with high concentrations of fibrinogen and soluble fibrin at different $\mathrm{pH}$ values, at different concentrations of plasma and protamine sulphate, and using different wavelengths and analysis times. Measurement of thrombin-induced fibrinogen-fibrin-transformation by the developed turbidimetric method, gave results that correlated well with the release of fibrinopeptide A.

The new protamine sulphate method for turbidimetric detcrmination of soluble fibrin is characterized by its practicability, rapid availability of reproducible, quantitative results, and its economy of reagents and time in single and serial analysis. Therefore it seems well-suited for the routine diagnosis of hypercoagulability with increased fibrinogen turnover.

\section{Introduction}

Fibrin monomers are intermediate products of the fibrinogen-fibrin-transformation, and they form soluble fibrin monomer complexes in plasma $(1,2)$. Since the fibrin monomers can aggregate possibly with fibrinogen and form dimers, trimers and even oligomers, the term soluble fibrin was established $(3,4)$.

Increased concentrations of soluble fibrin are an early and sensitive indicator for hypercoagulability with increased fibrinogen turnover $(5-7)$.

For routine determination of soluble fibrin, the paracoagulation test with protamine sulphate was considered practical: After fibrin monomers are released from their complex bond with fibrinogen, the protam: ine sulphate supposedly causes polymerisation of the monomers (gelation), or it may possibly induce the polymerisation of complexes $(8-10)$. Depending on the concentration, either fibrin gel or tiny fibrin strands are formed $(11-13)$, or the fibrinogen can even precipitate $(14-16)$. The resulting turbidity was measured photometrically by Lipinski in 1968 (17). In subsequent modifications of this original protamine sulphate test the evaluation was simply done by visual estimation and assignation of titres or description of turbidity $(6,11-13)$. Due to a lack of specifity, especially with regard to fibrinogen, none of the numerous modifications was successful $(14,15,18)$.

The general aim of our investigation was the sensitive and quantifiable determination of the soluble fibrin aggregation in a turbidimeter or nephelometer. A preliminary modification of the protamine sulphate test (19) showed an adequate validity in a preceeding study with approximately 1000 patients; and in these analyses, no interference by fibrinogen was observed.

The intention of the present study was to develop a new turbidimetric method for detection of the protamine sulphate induced aggregation of soluble fibrin by systematic modification of the test conditions. This method should provide a simple, rapid and quantifiable measurement of soluble fibrin without interference from fibrinogen in plasma. 


\section{Materials and Methods}

Citrate plasina was obtained by centrifugation $(2000 \mathrm{~g}, 10 \mathrm{~min})$ of blood anticoagulated with sodium citrate $(0.015 \mathrm{~mol} / \mathrm{l})(1: 10$ by vol.). Plasma triacylglycerol and cholesterol concentrations were less than $3 \mathrm{~g} / \mathrm{l}$. Special anticoagulation was required for the radioimmunoassay of fibrinopeptide $A$ and the tests for fibrin(ogen) degradation products.

Plasina samples with high fibrinogen concentrations (3.5 to 5.4 $\mathrm{g} / \mathrm{l})$ were selected from samples taken from healthy blood donors (according to the standards for blood donor recruitment, no leukocytosis). Further samples with high fibrinogen concentrations (4.0 and $6.5 \mathrm{~g} / \mathrm{l}$ ) were selected from samples from patients, not seriously ill, and most of them in ambulatory care. Criteria for selection were normal values in blood coagulation tests (thromboplastin time, partial thromboplastin time, thrombin time, antithrombin III, soluble fibrin-erythrocyte-agglutination test (20), fibrin(ogen) degradation products).

Plasma samples with high soluble fibrin concentrations were obtained by incubation of citrate plasma with thrombin (25 NIH units per l) from Hoffmann-LaRoche, Switzerland, at $30^{\circ} \mathrm{C}$. At 0 and after $0.5,1.0,1.5 \ldots 5,10,15,20,30$ minutes, thrombin-induced fibrinogen transformation was terminated by addition of hirudin (10000 units per 1 ) from Pentapharm, Switzerland. No clots were visible during the first 10 minutes of thrombin action.

A serial dilution of soluble fibrin plasma was performed by diluting this soluble fibrin plasma (thrombin-treated as described) in the same plasma before thrombin addition.

Standards of soluble fibrin were prepared using desAA-fibrin (fibrinogen devoid of both fibrinopeptides A) from Biopool, Sweden, dissolved in $1 \mathrm{~mol} / 1 \mathrm{NaBr}$ or isotonic $\mathrm{NaCl}$ solution. Serial dilution of these standards resulted in final concentrations of 5 to $1000 \mathrm{mg} / \mathrm{l}$ after adding desAA-fibrin solutions to plasma $(100 \mu \mathrm{l}+900 \mu \mathrm{l})$.

Methods and reagents of routine diagnosis were used to determine fibrinogen concentrations (method by Clauss), thromboplastin time, partial thromboplastin time, thrombin time, antithrombin III concentrations and fibrin(ogen) degradation products (latex agglutination test with a special anticoagulant from Wellcome, United Kingdom).

Soluble fibrin-erythrocyte-agghtination-test (20) was used for the determination of soluble fibrin by the agglutination of fibrin monomer-coated erythrocytes (FM-Test from Boehringer Mannheim, FRG). If agglutination occurred, the sample was $1: 2$ diluted with plasma without soluble fibrin.

Fibrinopeptide A RIA: Determination of plasma fibrinopeptide A was performed radioimmunologically with the FPA-J125RIA-Kit (Mallinckrodt, USA) after precipitation of plasma fibrinogen with bentonite (special anticoagulation with thrombin inhibitor).

Turbidimetry of protamine sulphate induced soluble fibrin aggregation: For the determination of soluble fibrin, citrate plasma and buffer were preincubated; after addition of protamine sulphate, the increase in turbidity was measured kinetically in a turbidimeter. The photometer "EPOS-Analyzer 5060" from Eppendorf (FRG) was suited for a short kinetic analysis; it permits the measurement of light absorbance in the $\mathrm{Hg}$-spectrum and is equipped for programmable automatic pipetting of samples, buffer and protamine sulphate solutions.

Standard procedure: $40 \mu \mathrm{l}$ citrate plasma and $185 \mu \mathrm{l} 0.1 \mathrm{~mol} / \mathrm{l}$ Tris buffer ( $\mathrm{pH} 6.5$, containing $\mathrm{NaCl}$ ) were preincubated for 156 seconds at $25^{\circ} \mathrm{C} ; 25 \mu \mathrm{l}$ of a $2 \mathrm{~g} / \mathrm{l}$ protamine sulphate dilution were added and after 12 seconds the increase in turbidity was measured at $334 \mathrm{~nm}$ over a timespan of 7 seconds. The result was calculated from $\Delta \mathrm{A} / \Delta \mathrm{t}: \Delta \mathrm{A} / \mathrm{min}=\left(\mathrm{A}_{19 \mathrm{~s}}-\mathrm{A}_{12 \mathrm{~s}}\right) \cdot 60 / 7$, with $A_{0 s}=$ addition of protamine sulphate; in printouts the absorbance values were multiplied by 10000 . Analyses were performed in triplicate, and any value differing from the other two was discarded.
In order to evaluate the test conditions each of the following parametcrs was varied independently: citrate plasma volume $(30,40$ or $50 \mu \mathrm{l})$, protamine sulphate volume $(15,20$ or $30 \mu \mathrm{l}$ of a protamine sulphate $\mathrm{NaCl}$-solution $(2 \mathrm{~g} / \mathrm{l})$ diluted from a $10 \mathrm{~g} / \mathrm{l}$ protamine sulphate solution in $10 \mathrm{~g} / \mathrm{l}$ benzyl alcohol $/ \mathrm{H}_{2} \mathrm{O}$ solution from Novo, Danmark), buffer $\mathrm{pH}$ value (Tris buffer with $0.1 \mathrm{~mol} / 1$ Tris in $0.15 \mathrm{~mol} / 1 \mathrm{NaCl}$ solution adjusted with $1 \mathrm{~mol} / 1 \mathrm{HCl}$ to $\mathrm{pH}$ values $6.5,7.0,7.5,8.0$; buffer volume adjusted to $250 \mu$ l total volume), wavelength (334, 405, 492, $546,578 \mathrm{~nm})$.

Total volume $(250 \mu \mathrm{l})$, temperature $\left(25^{\circ} \mathrm{C}\right)$, time of plasmabuffer-preincubation (156 s), protamine sulphate incubation (12 s) and absorbance measurement $(7 \mathrm{~s})$ were kept constant.

The evaluation of the test conditions was performed in samples with high and low fibrinogen concentrations before and after thrombin addition (stopped by hirudin) to produce soluble fibrin.

The kinetics of protamine sulphate-induced soluble fibrin aggregation were investigated in plasma samples with a high concentration of soluble fibrin or fibrinogen by continuous measurement of the resulting turbidity after addition of protamine sulphate. Furthermore, samples with high concentrations of soluble fibrin were incubated with thrombin in excess; in other series they were treated with streptokinase from Behring (FRG) and then analysed in the soluble fibrin turbidimetry again.

In fibrinogen-fibrin-turnover (in vitro induced by thrombin) soluble fibrin was determined by the turbidimetry, by the erythrocyte agglutination-test and from the release of fibrinopeptide A. The results were compared and related to the duration of thrombin action.

\section{Results}

Evaluation of the test conditions

\section{Wavelength}

Aggregation of soluble fibrin induced by protamine sulphate causes a stronger signal at shorter wavelengths, which shows a linear dependence on $\mathrm{Hg}$ spectrum frequency (fig. $2 \mathrm{a}$ ); the same dependence was shown by spectrophotometry in the continuous spectrum between 800 and $330 \mathrm{~nm}$ ( 3 minutes after addition of protamine sulphate).

\section{Kinetics}

The continuous increase in turbidity after addition of protamine sulphate was measured during $140 \mathrm{~s}$ in 3 samples with different concentrations of soluble fibrin (fig. 1). The greatest increase in turbidity $\Delta \mathrm{A} / \Delta \mathrm{t}$ was seen immediately after addition of protamine sulphate; by using a 1:2 diluted soluble fibrin-sample, the initial slope was reduced by $50 \%$.

In a plasma sample with a high fibrinogen concentration $(5.5 \mathrm{~g} / \mathrm{l})$, an increase in turbidity was also noticed after addition of protamine sulphate, but distinctly less than in a sample with a high concentration of soluble fibrin. The sample was examined before and after addition of $500 \mathrm{mg} / \mathrm{l}$ desAA-fibrin standard; in the sample containing desAA-fibrin the turbidity in- 


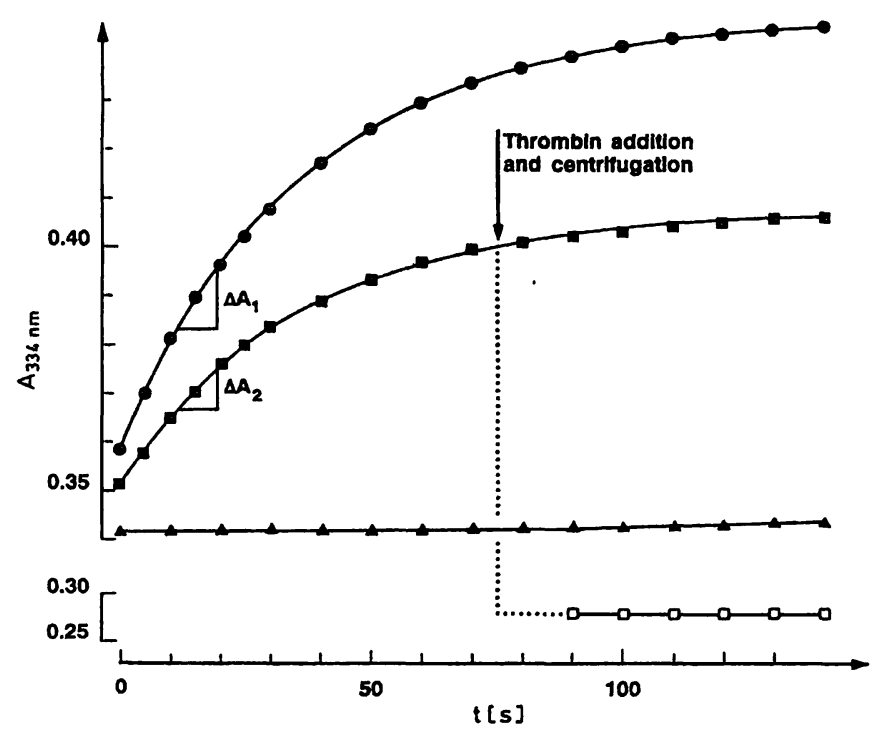

Fig. 1. Kinetics of turbidity changes: Continuous measurement of turbidity after the addition of protamine sulphate to a plasma sample before $(\Delta)$ and after addition of thrombin ( 0 ) and in a sample obtained from a $1+1$ dilution of both (a); $\Delta \mathrm{A}=\mathrm{A}_{19 \mathrm{~s}}-\mathrm{A}_{12 \mathrm{~s}} ; \Delta \mathrm{A}_{1}=0.0121$, $\Delta \mathrm{A}_{2}=0.0066$. Clotting in the sample was induced by addition of thrombin ( 5000 units/l); after centrifugation of the sample and addition of protamine sulphate, turbidity was again recorded continuously ().

crease was about $\mathrm{A}=0.0107$ from the 12 th to the 19th second after addition of protamine sulphate; in comparison the sample without desAA-fibrin showed an increase of only $\mathrm{A}=0.0006$ in the same timespan.

\section{$p H$ Value and concentrations in the assay}

In order to optimize the test conditions, $\Delta \mathrm{A} / \mathrm{min}$ was examined in samples with high fibrinogen and fibrin concentrations (thrombin-induced) in dependence on the $\mathrm{pH}$ value and on plasma- and protamine sulphate concentration.

Maximal changes in absorbance were obtained upon buffering the test solution at $\mathrm{pH} 6.5$ to $7.5(0.1 \mathrm{~mol} / 1$ Tris). Above $\mathrm{pH} 7.0$, high fibrinogen concentrations also caused increasing signals. Further studies were therefore performed at $\mathrm{pH} 6.5$ to 7.0 (not shown).

Figure $2 \mathrm{c}$ shows the linear increase in $\Delta \mathrm{A} / \mathrm{min}$ after increasing the concentration of protamine sulphate and in a set of curves for various dilutions of plasma. To demonstrate the relation between the specific effect of protamine sulphate on soluble fibrin and its unspecific effect on fibrinogen, the ordinate in figure $2 \mathrm{~d}$ shows the quotient of 'turbidity increase in samples with high concentrations' of soluble fibrin' and the 'turbidity increase in samples with high fibrinogen concentrations'. Above protamine sulphate concentrations of $0.2 \mathrm{~g} / 1$ the fibrinogen sensitivity increased more than the soluble fibrin sensitivity (fig. $2 c-2 d$ ).
The increase of turbidity $(\Delta \mathrm{A} / \mathrm{min})$ was not clearly dependent on the plasma concentration in the test. Moreover, the curves were dependent on the protamine sulphate concentration (set of curves for 0.12 , $0.16,0.20,0.24 \mathrm{~g} / \mathrm{l})$. At higher protamine sulphate concentrations, $\Delta \mathrm{A} / \mathrm{min}$ increased as the plasma concentrations in the test increased.

\section{Sensitivity/linearity}

The results of the turbidimetric method correlated well with the concentration of soluble fibrin in a dilution series ( $r=0.99, \mathrm{n}=8$ ), using the soluble fibrin plasma and plasma before thrombin treatment as diluent (fig. $2 \mathrm{~b}$ ); the results were linearly dependent on soluble fibrin concentrations in the range of $\Delta \mathrm{A}$ / min from 0.010 to 0.150 ; and there was also a linear relationship with the serial dilution of desAA-fibrin in plasma. $1 \mathrm{~g} / \mathrm{l}$ desAA-fibrin resulted in a $\Delta \mathrm{A} / \mathrm{min}$ of 0.179 and $0.1 \mathrm{~g} / 1$ in $\Delta \mathrm{A} / \mathrm{min}$ of 0.0196 . Concentrations of less than $0.015 \mathrm{~g} / 1$ desAA-fibrin were not reliably detected by the new turbidimetric method.

\section{Reproducibility}

The standard deviation of 10 samples with different concentrations of soluble fibrin, each determined 20 times in triplicate $(5$ different series with different laboratory personnel), was less than $5 \%$ of the mean in the range of $\Delta \mathrm{A} / \mathrm{min}$ from 0.015 to 0.150 , and up to $10 \%$ in samples with lower or higher values.

$5 \%$ of the values in a double determination differed more than $\Delta \mathrm{A} / \mathrm{min}>0.003$ and more than $15 \%$ from each other. Additional measurements generally confirmed the correspondence of at least 2 values. Therefore measurements were performed in triplicate and the median was taken as the result. Within-run coefficients of variation ranged from 1.7 to $7.4 \%$ (tab. 1).

Tab. 1. Mean values and within-run coefficients of variation

\begin{tabular}{ll}
\hline $\begin{array}{l}\text { Mean } \\
(\Delta \mathrm{A} / \mathrm{min})\end{array}$ & $\begin{array}{l}\text { Within-run } \mathrm{CV} \\
(\%)\end{array}$ \\
\hline 0.1918 & $1.7 \%$ \\
0.0721 & $2.9 \%$ \\
0.0508 & $3.1 \%$ \\
0.0432 & $4.9 \%$ \\
0.0164 & $3.7 \%$ \\
0.0076 & $7.4 \%$ \\
0.0028 & $6.5 \%$ \\
\hline
\end{tabular}

Specificity and validity

Addition of excess thrombin (5000 NIH units per l) caused an immediate decrease in values obtained by the soluble fibrin turbidimetry with formation of clots. 

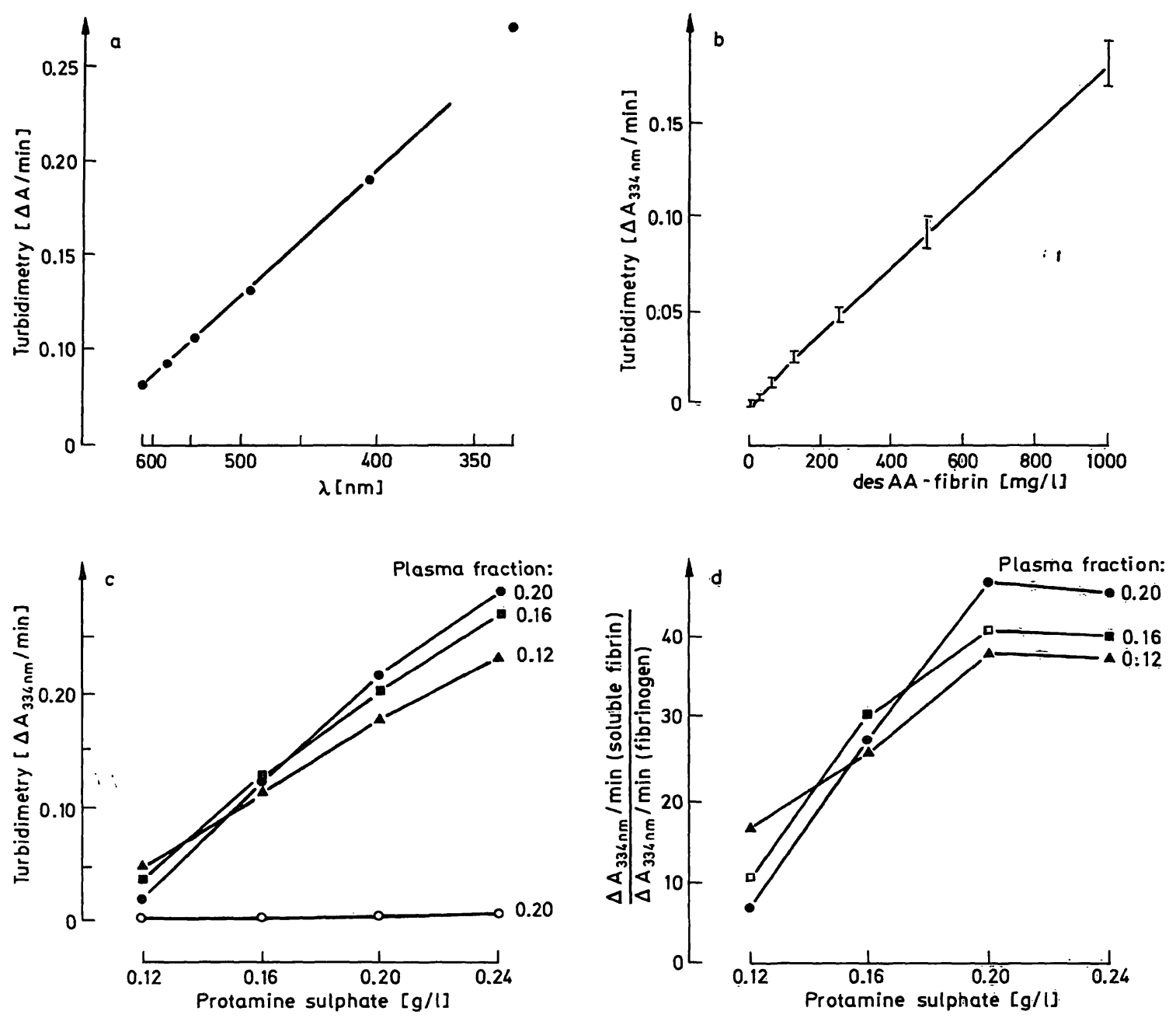

Fig. 2. Evaluation of the test conditions. Standard test condition: preincubation of $40 \mu \mathrm{l}$ citrate plasma with $185 \mu \mathrm{l} 0.1 \mathrm{~mol} / 1$ Tris-buffer ( $\mathrm{pH} \mathrm{6.5,} \mathrm{containing} \mathrm{NaCl}$ ) for 156 seconds at $25^{\circ} \mathrm{C}$, addition of $25 \mu \mathrm{l} 2 \mathrm{~g} / \mathrm{l}$ protamine sulphate solution; after incubation for another 12 seconds the increase in turbidity was measured for 7 seconds in a turbidimeter at $334 \mathrm{~nm}$ with final calculation of $\Delta \mathrm{A} / \mathrm{min} . \Delta \mathrm{A} / \mathrm{min}$ in dependence on varied parameters:

(A) Dependence on wavelength of the $\mathrm{Hg}$-spectrum; abscissa is divided reciprocally.

(B) Dependence on concentration of desAA-fibrin in plasma (median, 20 to $80 \%$ quantile).

(C) Dependence on protamine sulphate concentration at various dilutions of plasma samples (indicated as fraction), samples with high soluble fibrin concentrations $(0, \boldsymbol{0}, \mathbf{\Delta})$ and high fibrinogen concentrations $(0)$.

(D) Dependence of quotient $\Delta \mathrm{A} / \mathrm{min}$ for the soluble fibrin sample divided by $\Delta \mathrm{A} / \mathrm{min}$ for the fibrinogen sample on protamine sulphate concentrations at various plasma dilutions (indicated as fractions).

Plasmin (induced by addition of streptokinase) caused a slower, but finally complete decrease without generation of fibrin strands.

Twenty five percent of the 500 patient plasma samples with high fibrinogen concentrations $(4-7 \mathrm{~g} / \mathrm{l})$ showed no elevation of turbidity. In $58 \%$ of 34 plasma samples from obviously healthy persons (blood donors) with fibrinogen concentrations from 4 to $5.5 \mathrm{~g} / \mathrm{l}$, soluble fibrin was not elevated $(\Delta \mathrm{A} / \mathrm{min}<0.004)$; the other 14 plasma samples yielded only slightly elevated values. $(\Delta \mathrm{A} / \mathrm{min}<0.012)$. More than $90 \%$ of normal subjects with fibrinogen concentrations less than $4 \mathrm{~g} / 1$ showed values in the developed method of less than $\Delta \mathrm{A} / \min =0.004$.
In a clinical study, healthy persons had distinctly lower values (mean of $\Delta \mathrm{A} / \mathrm{min}=0.0022, \mathrm{n}=45$ ) than patients from general care wards (mean of $\Delta \mathrm{A}$ / $\min =0.0305, \mathrm{n}=220$ ) and patients from intensive care wards (mean of $\Delta \mathrm{A} / \mathrm{min}=0.0508, \mathrm{n}=598$ ); intensive care patients suffering from blood coagulation disorders showed very high values up to $\Delta \mathrm{A} / \mathrm{min}$ of 0.300 (mean of $\Delta \mathrm{A} / \mathrm{min}=0.0885, \mathrm{n}=127$ ).

The increase of fibrinopeptide $A$ and the soluble fibrin turbidimetric values, in dependence on the duration of the in vitro thrombin action, is shown in figure 3 (computer-aided curve). The concentrations of fibrinopeptide $\mathrm{A}$ described an initially linear increase, rapidly attaining high values. The results of the sol- 


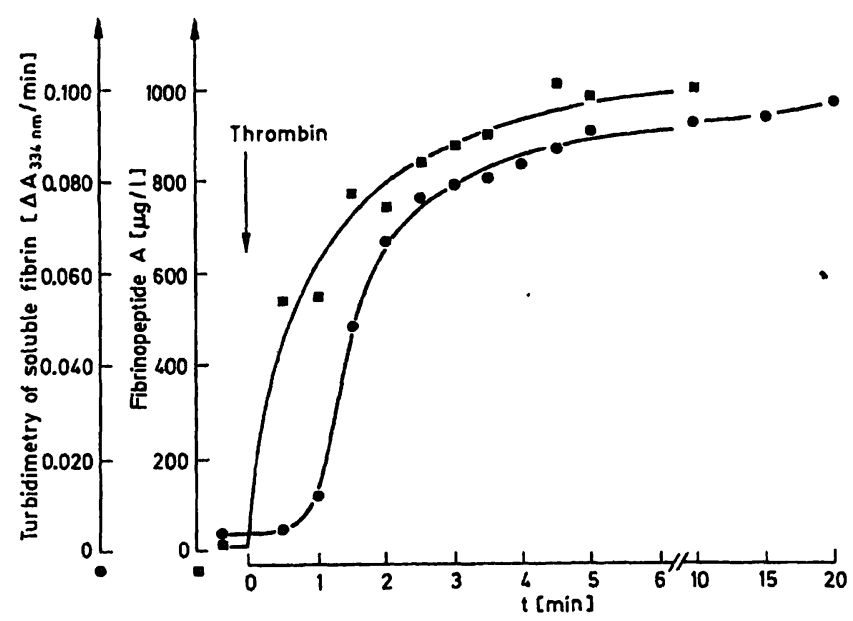

Fig. 3. Comparison of the results from soluble fibrin turbidimetry (0) and fibrinopeptide A RIA ( $\boldsymbol{\theta})$ in dependence on the duration of thrombin action in the plasma samples (computer-aided curve fitting).

uble fibrin turbidimetry exhibited a sigmoid curve with an initial smaller and then larger increase and a final decline. After 8 minutes both curves ended in a plateau; high plasma concentrations persisted for the next 20 minutes. Finally the soluble fibrin turbidimetry values decreased slowly, producing visible thin fibrin strands.

The curve for the 2 methods was easily reproducible during 8 test series in which fibrinogen transformation was induced in various ways; only the initial slope differed and consequently the plateau with maximal values.

The comparison of turbidimetry and erythrocyte-agglutination test in the determination of soluble fibrin, produced in vitro by thrombin addition, is shown in figure 4.

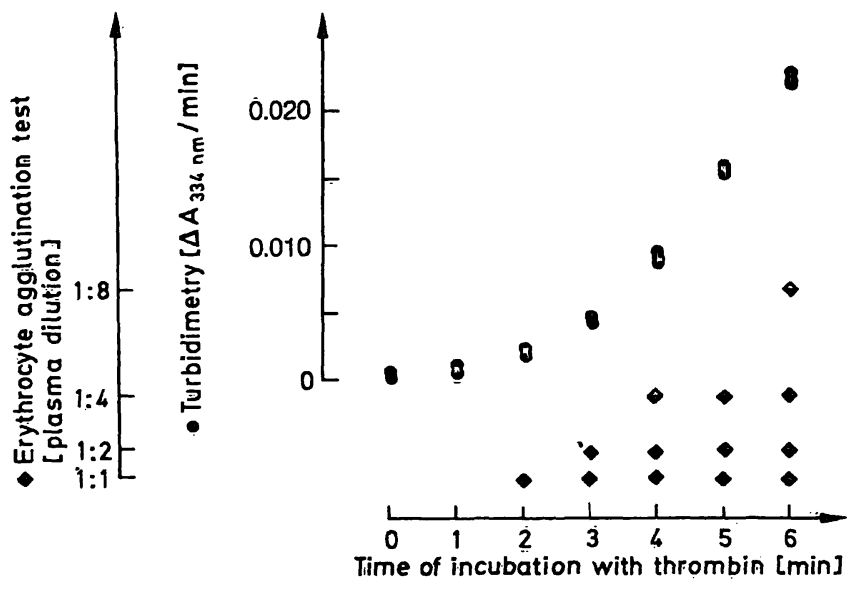

Fig. 4. Comparison of the determination of soluble fibrin by the turbidimetric method (๑) and by the erythrocyteagglutination-test $(\diamond)$ in dependence on the duration of thrombin action in plasma samples $(\bullet=$ positive erythrocyte agglutination test in $1: 1,1: 2,1: 4$ or $1: 8$ diluted plasma samples, $\diamond=$ slight or non-reproducible agglutination).

\section{Discussion}

Soluble fibrin is an early and sensitive indicator of hypercoagulability with increased fibrinogen turnover $(5-7)$. For routine soluble fibrin diagnosis a method has been developed by systematic modifications of the test conditions. This method allows an adequately sensitive and quantitative determination of soluble fibrin by means of protamine sulphate-induced aggregation of soluble fibrin without interference from fibrinogen; the test can be performed simply and rapidly.

\section{Evaluation of the test conditions}

\section{Light scattering}

Light is diffusely reflected in colloidal solutions; nephelometers detect scattered light directly, turbidimeters indirectly through loss of intensity. Although the nephelometer tends to be more sensitive at low turbidity, the present turbidimetric method yields more sensitive and reproducible results, through fully automatic analysis and precise kinetic measurements, than preliminary experiments with a laser-nephelometer (19). Both turbidimetry and nephelometry allow quantitative measurements, and they are considerably more sensitive than visual estimations, which are evaluated subjectively in titres, or only descriptively.

\section{Wavelength}

In spectrophotometry the aggregation of soluble fibrin causes a stronger signal at shorter wavelengths apparently following Raleigh's law of light scattering $(\mathrm{A}=\mathrm{k} \times$ frequency). Thus all further experiments were performed at $334 \mathrm{~nm}$.

Recent kinetic investigations of fibrin aggregation were- also done at short wavelengths $(21-23)$. In contrast, measurement at $610 \mathrm{~nm}$ as recommended by Lipinski (17) decreased the sensitivity. Turbidimetry of clotting in routine diagnostic tests is usually recorded at $550 \mathrm{~nm}$.

\section{Kinetics}

The continuous measurement of protamine sulphateinduced turbidity $(\Delta \mathrm{A} / \Delta \mathrm{t})$. showed the greatest increase immediately after addition of protamine sulphate. The initial velocity was proportional to soluble fibrin concentrations in plasma (fig. 1), as already shown by Latallo in kinetic investigations of fibrin polymerisation (21). Thus further measurements were performed with both incubation (12s) and measurement $(7 \mathrm{~s})$ times as short as possible (limited by the apparatus). This yields a high rate of sample analyses 
(30 seconds per triple measurement). Moreover the short timing is important to avoid disturbing influences of fibrinogen.

Interpolation of 6 single values for each measurement without any movement of the cuvette in the beam results in good reproducibility, in spite of the extremely short time of measurement. The initial turbidity of the plasma sample does not affect the results during kinetic measurements. Earlier studies used endpoint measurements after 5-10 minutes or visual estimations $15-30$ minutes after addition of protamine sulphate $(11,12,24-26)$. In some studies additional controls were performed after 24 hours, in order to avoid false positive results through precipitation of fibrinogen $(11,13)$.

pH-value, protamine sulphate concentrations and plasma fractions were varied in order to establish optimal test conditions, as in earlier studies of this kind $(12,13,19,21,24,27)$.

Good results were obtained at $p H$ 6.5-7.0. Buffers other than Tris, such as phosphate or PIPES solutions, all tested in the same manner, resulted in less soluble fibrin sensitivity or a greater fibrinogen influence. Using $0.1 \mathrm{~mol} / 1$ Tris at $\mathrm{pH} 6.5$, the final mixture after protamine sulphate and plasma addition resulted in pH 6.7 to 6.8 .

An acid $\mathrm{pH}$ value is intended to avoid a spontaneous polymerisation of soluble fibrin $(21,26)$. A pH value between $5.8-7.0$ leads to lateral polymerisation of soluble fibrin, which produces thick fibrils and therefore a photometrically well detectable turbidity $(23$, 27). Only a few authors have used $\mathrm{pH}$ values outside this range $(14,27)$.

Protamine sulphate concentrations of $0.2 \mathrm{~g} / \mathrm{l}$ were suitable. Several other authors have used protamine sulphate concentrations up to $2 \mathrm{~g} / 1(14,25)$, and the effect of such concentrations on fibrinogen precipitation has been discussed controversially $(10,11,15$, 24, 29). Gurewich also used final protamine sulphate concentrations of $0.2 \mathrm{~g} / \mathrm{l}$ or less in order to avoid fibrinogen precipitation (11). Gurewich's serial dilution test with protamine sulphate concentrations of $0.5-0.06 \mathrm{~g} / 1$ is known to be a reliable and sensitive, but time consuming protamine sulphate test for the detection of soluble fibrin $(6,30)$. Even though protamine sulphate is a biological product, another preparation with protamine sulphate from Sigma (USA) performed identically.

In contrast to the linear dependency of the turbidity increase on soluble fibrin concentration in plasma (fig. $2 \mathrm{~b}$ ), there was no clear cut dependency of the turbidity change $\Delta \mathrm{A} / \mathrm{min}$ on the plasma fraction in the final test mixture (not shown); an increase of $\Delta \mathrm{A} / \mathrm{min}$ in dependence on plasma concentration was noticed only in the presence of higher concentrations of protamine sulphate. The observation that a plasma concentration of $24 \%$ did not yield a two fold greater increase in turbidity than a plasma concentration of $12 \%$ might be due to the fact that not only soluble fibrin is diluted but all plasma proteins, and albumin for example is said to have an inhibitory effect on protamine sulphate. A plasma fraction of 0.20 in the test provided better results than concentrations of 50 to $90 \%$ as required for visual estimations by other authors $(11,12,24-26)$.

In conclusion, when compared with former modifications with visual estimations, this new method for the detection of protamine sulphate-induced aggregation of soluble fibrin in a turbidimeter provides low protamine sulphate and plasma concentrations; it is characterized by a kinetic measurement over a short time period, also with a short incubation time. An adequately sensitive determination of soluble fibrin without interference from plasma fibrinogen was possible only under these specific test conditions.

\section{Specificity}

The in vitro thrombin-induced fibrinogen-fibrin turnover was detected equally well by fibrinopeptide $\mathrm{A}$ RIA and soluble fibrin turbidimetry. The values obtained with both methods rose in dependence on the thrombin action up to a plateau (fig. 3). A small delay in the increase of turbidimetric values may be due to a lack of detectable aggregation of soluble fibrin at very low concentrations of soluble fibrin.

Apart from the correlation with the soluble fibrinerythrocyte-agglutination test, in other in vitro studies the results of the turbidimetry correlated well $(n=51$, $r=0.96$ ) with the immunological determination of soluble fibrin $(31,32)$, and $(n=36, r=0.94)$ with the soluble fibrin determined by the tissue plasminogen activator test $(31,33)$. In addition to this correlation with the immunological and the functional test, experiments with streptokinase and thrombin supported the assumption that the turbidity is caused by a clottable fibrinogen derivative.

The absence of interference by fibrinogen was demonstrated by using plasma samples, which provided normal values in the newly developed turbidimetric method in spite of high fibrinogen concentrations up to $6.5 \mathrm{~g} / \mathrm{l}$. Nevertheless, high turbidimetric values were more frequent at high fibrinogen concentrations, thus supporting former assumptions on fibrinogen turnover (1). 
The influence of plasma proteins, in particular of fibrin(ogen) degradation products (29), plasma lipids and drugs has not yet been elucidated completely; late fibrin(ogen) degradation products apparently do not cause positive results, whereas early fibrin(ogen) degradation products are supposed to be detected; Ddimers do not seem to result in false positive values.

\section{Application of the new turbidimetric method}

The reproducibility of the results was adequate (tab. 1). Triplicate measurements were performed in order to eliminate values differing from the other two; these were possibly due to the small volume and short time necessary. In routine diagnosis, the median was taken as the result. In spite of the short measuring time of 7 seconds, high reproducibility is obtained by the fully automatic analysis procedure with exact pipetting and sensitive optical measurements.

The analytical procedure is simple and can also be performed by untrained laboratory personnel with a minimum of labour. Soluble fibrin results could be obtained more simply, reliably and quickly than the fibrinopeptide A RIA results.

The high rate of sample throughput, the very low cost of reagents (less than $1 \%$ of Quick test) and small amount of plasma required are all criteria, which help to make this test economical, an important requirement for routine diagnosis.

In conclusion, the practicability and rapid availability of reproducible quantitative results are important criteria for the application of the newly developed turbidimetric method in determination of soluble fibrin especially in the routine diagnosis of hypercoagulability with an increased fibrinogen turnover.

\section{Acknowledgement}

We thank Prof. S. Lenzen for his revision of this manuscript, as well as for his permanent efforts in providing us insights into general scientific work.

\section{References}

1. Brass, E. P., Forman, W. B., Edwards, R. V. \& Lindan, O. (1976) Thromb. Haemost. 36, 37-48.

2. Smith, G. F. \& Bang, N. U. (1972) Biochemistry 16, $2958-$ 2966.

3. Alkjaersig, N. \& Fletcher, A. P. (1983) Biochem. J. 213, $75-83$.

4. Roetker, J., Preissner, K. T. \& Müller-Berghaus, G. (1986) Eur. J. Biochem. 155, 538-588.

5. Bick, R. L. (1981) Annals NY Acad. Sci. 370, 843-850.

6. Kisker, C. T. (1979) Am. J. Clin. Pathol. 72, 405-409.

7. Müller-Berghaus, G. \& Hasegawa, H. (1983) Bibl. Haematol. 49, 3-13.

8. Derechin, M. (1955) Rev. Hematol. 10, 35-40.

9. Hudry-Clergeon, A., Marguerie, G., Point, L. \& Suscillon, M. (1975) Thromb. Res. 6, 533-541.

10. Latallo, Z. S., Mattler, L. E., Bang, N. U., Hansen, M. S. \& Chang, M. L. (1976) Biochim. Biophys. Acta 402, 69-80.

11. Gurewich, V. \& Lipinski, B. (1976) Am J. Clin. Pathol. 65, 397-401.

12. Gurewich, V., Lipinski, B. \& Lipinska, I. (1973) Thromb. Res. 2, 539-556.

13. Niewiarowski, S. \& Gurewich, W. (1971) Lab. Clin. Med. $77,665-667$.

14. Latallo, Z. S., Wegrzynowicz, Z., Budzynski, A. Z. \& Kopec, M. (1971) Scand. J. Haematol. 13 (suppl.), 151-162.

15. Schwabe, G., Heene, D. L. \& Krause, W. (1972) Verh. Dtsch. Ges. Inn. Med. 78, 719-723.

16. Stewart, G. I. (1971) Scand. J. Haemațol. 13 (suppl.), 1651.78.

17. Lipinski, B. \& Worowski, K. (1968) Thromb. Diath. Haemorrhag. 20, 44-49.

18. Lipinski, B., Kotelba-Witkowska, B. \& Zajdel, M. (1971) In: Abstracts of 13. Int. Congress for Hematology, München 1970 (Kaulla v., K. N., ed.) Springfield, Illinois.

19. Wieding, J. U., Eisinger, G. \& Köstering, H. (1986) In: Rationelle Therapie und Diagnose von hämorrhagischen und thrombophilen Diathesen (Wenzel, E., Hellstern, P., Morgenstern, E., Köhler, M. \& Blohn v., G., eds.) pp. 2.79-2.82, Schattauer Verlag, Stuttgart.

20. Largo, R., Heller, V. \& Straub, P. W. (1976) Blood 47, 991-1002.

21. Latallo, Z. S., Fletcher, A. P., Alkjaersig, N. \& Sherry, S. (1962) Am. J. Physiol. 202, 675-680.

22. Sato, H. \& Nakajima, A. (1984) Thromb. Res. 33, 645651.

23. Usero, J. L., Burguillo, F. J., Izquierdo, C., del Arco, A. \& Herraez, M. A. (1984) Int. J. Biochem. 16, 553-559.

24. Kidder, W. R., Patch, M. J., Logan, L. J. \& Rapaport, S. J. (1972) Am. J. Clin. Pathol. 58, 675-686.

25. Musumeci, V., Marra, R., Zappacosta, B., Carloni, L. \& Cristofari, C. (1980) Thromb. Res. 17, 125-132.

26. Sasaki, T., Page, I. \& Shainoff, R. (1966) Science 20, 10691071.

27. Sanfelippo, M. I., Stevens, D. I. \& Koenig, R. R. (1971) Am. J. Clin. Pathol. 56, 166-173.

28. Nair, C. H., Shah, G. H. \& Dhall, D. P. (1986) Thromb. Res. 42, 809-816.

29. Latallo, Z. S., Fletcher, A. P., Alkjaersig, N. \& Sherry, S. (1962) Am. J. Physiol. 202, 681-686.

30. Zielinsky, A., Altman, R. \& Rouvier, I. (1976) Thromb. Haemost. 36, 165-172.

31. Wieding, J. U., Eisinger, G. \& Köstering, H. (1987) In: Fibrinogen and its derivatives (Lowe, G. D. O., Douglas, J. T. \& Forbes, C. D., eds.) pp. 187-190, Elsevier Science Publishers, Amsterdam.

32. Scheefers-Borchel, U., Müller-Berghaus, G., Fuhge, P., Eberle, R. \& Heimburger, N. (1985) Proc. Natl. Acad. Sci. USA 82, $7091-7095$.

33. Wiman, B. \& Ranby, M. (1986) Thromb. Haemost. 55. 189-193.

Dr. J. U. Wieding

Hämatologic der Universitätsklinik

D-3400 Göttingen 
